\title{
Relationship of debris flows owing to climate change: Korea's case
}

\author{
A. Cha \& T. H. Kim \\ National Disaster Management Institute, \\ Ministry of Safety and Administration, Republic of Korea
}

\begin{abstract}
The climate change drastically modifies the earth's environment and the landscape is easy to be altered by this global phenomenon. Transforming landscapes which lose their own stability usually results in forms of the ground movements such as landslides. Identifying landslide prone areas, mapping landslides, and evaluating expected risks to people, property, environment, and other resources are, therefore, important issues which are closely related to land use, engineering design work, and emergency planning in order to reduce the impacts by landslides. In this study, we examined the possibilities of identifying unstable areas where landslides would occur. These are based on the statistical evaluation of orientation data representing geomorphological characteristics of the ground surface. Practical applications to recent landslides which occurred in Korea showed the technology we proposed is well delineated the potential susceptibility of landslides before tragic events happened.

Keywords: climate change, precipitation, landslide, debris flow.
\end{abstract}

\section{Introduction}

The climate change is the gradual conversion of the current climate by natural and/or anthropogenic causes and drastically modifies the earth's environment and the landscape. Increasing awareness of the socio-economic consequence of the climate change and growing pressure of urbanization on the environment would attract more global attention on landslides disasters including debris flows than ever before. Unexpected precipitation and temperature caused by climate change will accelerate this awareness. 
In this study, therefore, the status of the climate change observed in the world and Korea is firstly discussed. The circumstances of landslides including debris flows with the climate change is briefly described and a new approach using statistical evaluation of orientation data representing geomorphological characteristics of the ground surface is introduced. Finally, a relationship between consequences of the climate change and debris flows is illustrated.

\section{Climate change and its impact}

The climate change is the gradual conversion of the current climate by natural and/or anthropogenic causes. It leads the general climate difference including the Greenhouse effect based on the human activities and natural phenomena such as solar activity, shift of earth's axis, and volcanic eruption. More direct effect of the climate change is, however, caused by the human including deforestation, increase of the Greenhouse Gases like $\mathrm{CO}_{2}$. This trend has become a global issue since the late 1980s.

The major causes of creating the Greenhouse effects are due to the high consumption of mineral and fossil fuels after the Industrial Revolution. The emission of Greenhouse Gases $\left(\mathrm{GHG}_{\mathrm{S}}\right)$ like $\mathrm{CFC}_{\mathrm{S}}, \mathrm{CH}_{4}, \mathrm{~N}_{2} \mathrm{O}$ and $\mathrm{CO}_{2}$ is highly increased since the middle $18^{\text {th }}$ century (fig. 1). In 2010, the global averaged mixing ratios of the latter three fractions $\left(\mathrm{CH}_{4}, \mathrm{~N}_{2} \mathrm{O}\right.$ and $\left.\mathrm{CO}_{2}\right)$ reached new highest points (WMO [1]).

Consequences of the climate change usually lead floods, heavy snow, and tsunamis, which are mainly caused by the temperature rise.

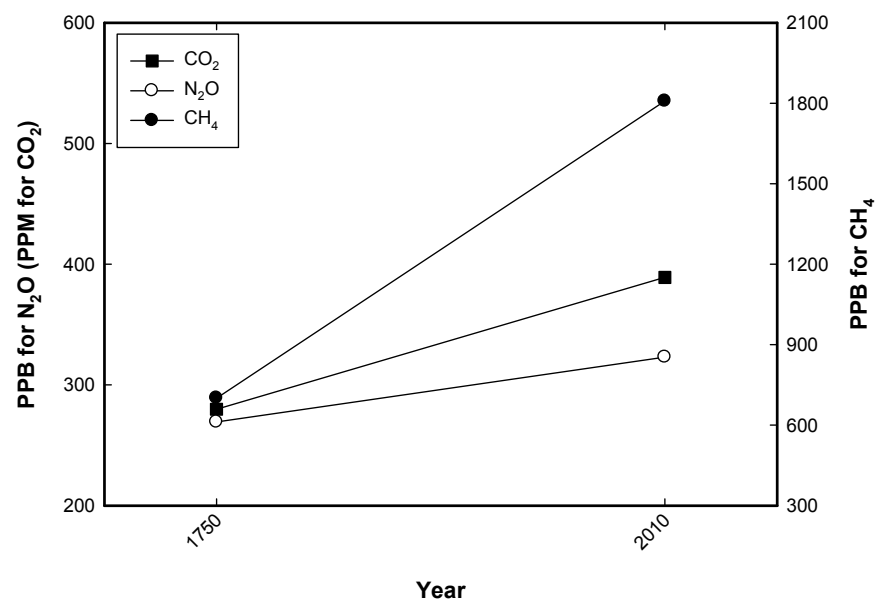

Figure 1: Global abundance and temporal variation of key Greenhouse Gases (Source: WMO [1]). 


\section{Trend of climate change in Korea}

Effects of the climate change on Korea are relatively faster than any other country in the globe and their consequences have increased gradually (NIER [2]). The trend of the climate change observed in Korea is well described in temperature and precipitation.

The annual temperature between 1961 and 1990 increased $0.4^{\circ} \mathrm{C}$ compared to the value from the past 30 years (1931-1960, fig. 2). The annual precipitation, although it showed a fluctuated behavior, has an increasing tendency in the long term perspective (KMA [3]). For example, the annual precipitation of the last 10 years (1996-2005) is recorded as 1,485.7 mm, which is $10 \%$ higher than average precipitation value (fig. 2). The daily number of heavy rainfall (daily precipitation over $80 \mathrm{~mm}$ ) is also noted as 28 days, which increased 8 days of the current record.

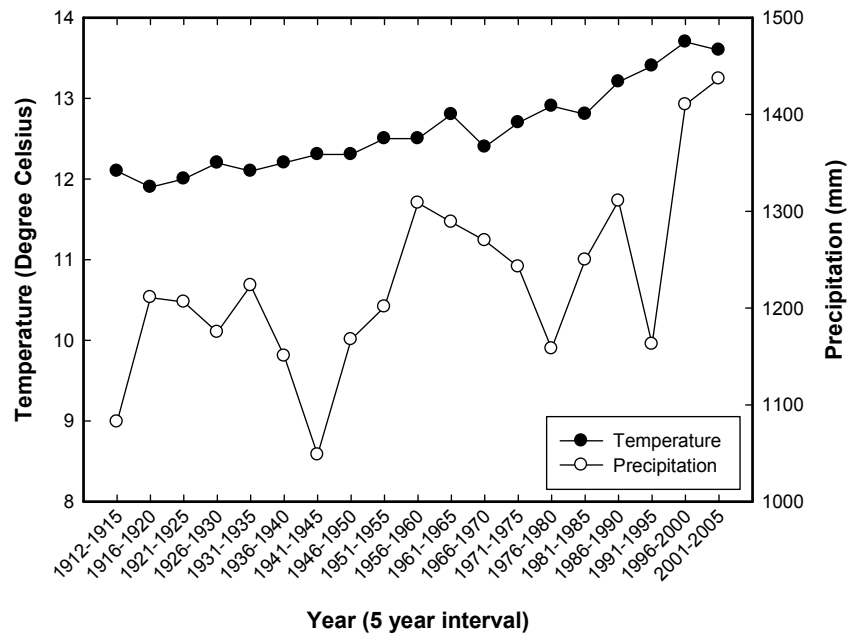

Figure 2: Variation of the annual temperature and precipitation from 1912 to 2005.

The results of the climate change have a strong relationship with water related disasters in Korea such as floods, drought, heavy snow, tsunami, and waterbloom (IPCC [4]). Particularly, the increasing rainfall intensity which is the consequence of decreasing rainfall days followed by the increasing precipitation may cause the frequency of torrential rainfall. This leads slope disasters such as debris flows, which are usually induced by heavy rainfall (fig. 3). 


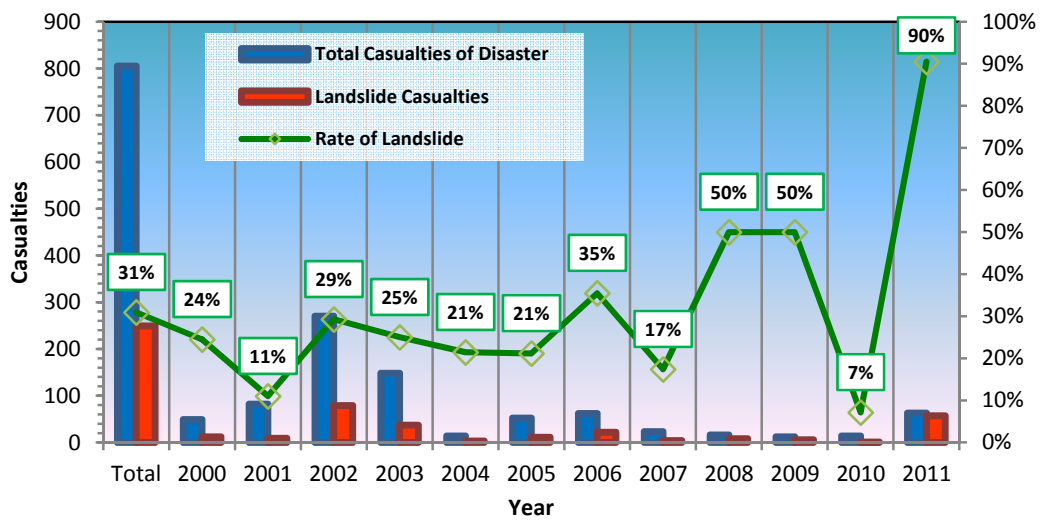

Figure 3: Total casualties of disaster, landslide and its rate, respectively.

\section{Debris flow disasters and their consequences}

Debris flows, one of the common landslide disasters, are frequently occurred in the world especially rainy season (June to September in Korea). Debris flows are made up of soil, rock, and water. Their flow characteristics depend on the water content, sediment size and/or sorting, and on the dynamic interaction between the solid and fluid phases. The modelling of such an interaction still remains a quite difficult task and the currently available computational models inevitably rely on simplifying assumptions (Pirulli and Sorbino [5]). Therefore, identifying landslide prone areas, mapping landslides, and evaluating expected risks to people, property, environment, and other resources are relatively difficult comparing other landslides disasters such as sliding, falling, etc. In order to reduce the impacts by debris flow, an approach identifying unstable areas where landslides would occur is proposed. It depends on the statistical evaluation of orientation data representing geomorphological characteristics of the ground surface.

\subsection{Statistical evaluation of the orientation data}

Quantifying the terrain is based on the orientation of planar surfaces that represent the terrain and can be calculated as unit vectors normal to the planar surfaces (Hobson [6]). Strength and dispersion of unit vectors can be used as an indicator of geomorphological features.

Based on the spherical distribution of directional and non-directional data it is shown that typical characteristics of spherical distribution are equivalent to the determination of eigenvalues and eigenvectors especially of a symmetric three by three matrix which comprises direction cosines (Watson [7]). Consider $N$ points of unit mass, $\left(l_{i}, m_{i}, n_{i}\right)$, where $i=1,2, \ldots, N$ and suppose that $\boldsymbol{u}$ is a true or preferred direction through the centre of the sphere, the moment of inertia $I$ of 
the set of $N$ points of unit observation data about $\boldsymbol{u}$ can be described as follows (Watson [7]):

$$
I=N-\boldsymbol{u}^{\prime} \boldsymbol{M} \boldsymbol{u}=N-\sum_{j=1}^{3} \sum_{\kappa=1}^{3} u_{j} M_{j \kappa} u_{\kappa}
$$

where, $\boldsymbol{M}$ is an orientation matrix, a three by three matrix consisting sums of cross products of direction cosines of the unit mass, $\left(l_{i}, m_{i}, n_{i}\right)$. It is given by:

$$
\boldsymbol{M}=\left(\begin{array}{ccc}
\sum l_{i}^{2} & \sum l_{i} m_{i} & \sum l_{i} n_{i} \\
\sum m_{i} l_{i} & \sum m_{i}^{2} & \sum m_{i} n_{i} \\
\sum n_{i} l_{i} & \sum n_{i} m_{i} & \sum n_{i}^{2}
\end{array}\right)
$$

The eigenvalues of $\boldsymbol{M}$ are calculated from roots of the characteristic equation, $\lambda_{i}\left(i=1,2,3 ; \lambda_{1}>\lambda_{2}>\lambda_{3}\right)$, and corresponding vectors are the eigenvectors, $v_{i}(i=1,2,3)$. Three eigenvalues are always positive and add to $N$ while three eigenvectors are always perpendicular to each other (Watson [7]). A normalized form of the eigenvalues can be obtained divided by the number of unit observation points $N$ :

$$
S_{j}=\frac{\lambda_{j}}{N}, j=1,2,3
$$

The evaluation of eigenvalues is especially beneficial when large amounts of field data, either geological or geomorphological, containing the directional characteristic of materials are acquired and compared. Woodcock [8] noted that the eigenvalue analysis would illustrate a relationship between the change of fabric shape and associated strain progression, which Mark [9] provided similar results from till fabrics.

Landslide studies using the characteristics of eigenvalues have been recently developed by Guth [10], McKean and Roering [11], Kasai et al. [12]. After Cruden [13] first calculated the axes of cylindrical folds with the eigenvalue technique. They focused on the recognition of topographic information to identify landslide characteristics and their kinematics.

\subsection{Overview of the study area in Umyeon Mountain in Korea}

The debris flow in the study area at Umyeon Mountain, Seoul, Korea was initiated by heavy rainfall both antecedent and daily rainfall. Saturated ground moved like a flow and hit residences and vehicles under the slope (figs 4 and 5).

The main cause of debris flow in Umyeon Mountain area was rainfall, which classify into the two different ones based on the temporal variation. Firstly, the 
antecedent rainfall fell two weeks before the landslide event and is recorded as $463.0 \mathrm{~mm}$. It fully saturated ground surface. Second, a heavy daily rainfall amounting $342.5 \mathrm{~mm}$ fell into the study area. It took about $74 \%$ of antecedent rainfall. The rainfall intensity of the first impacted landslide area was $68.5 \mathrm{~mm} / \mathrm{hr}$. Based on the rainfall history, debris flow occurred in the study area was initiated by the high intensity daily rainfall with the help of saturated ground by long-term antecedent rainfall.

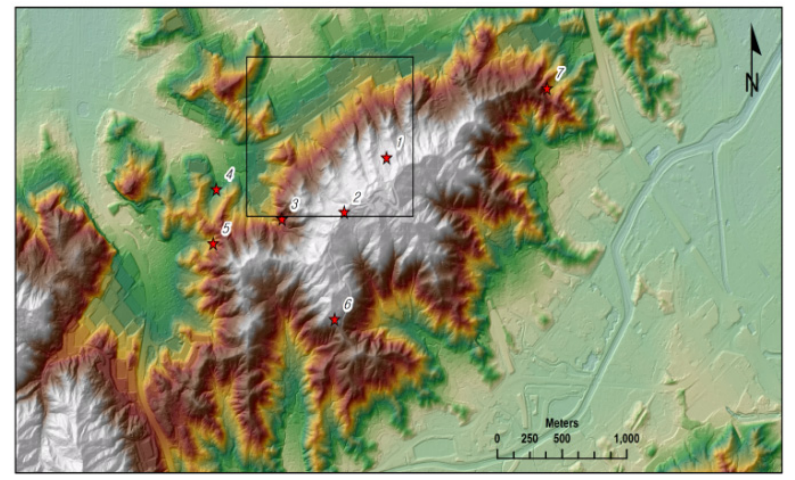

Figure 4: Overview of the study area and debris flow locations (1 and 2: apartments; 3: temple; 4 to 7: residential areas). Area outlined in the figure is shown in Figure 8.

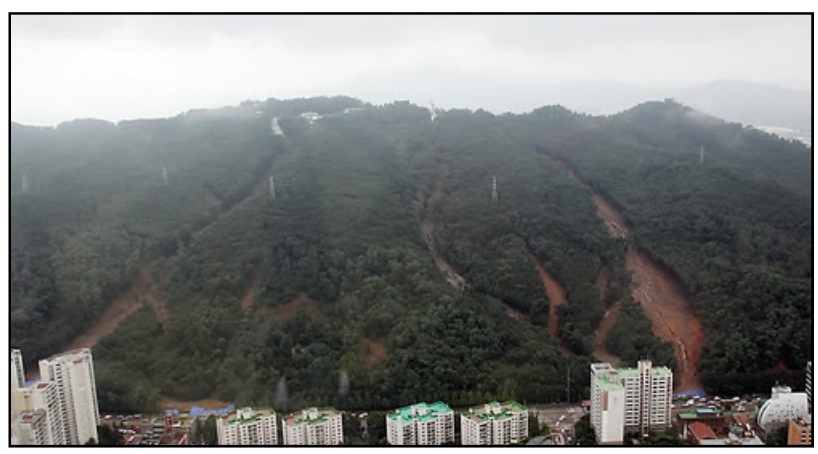

Figure 5: Aerial view of the study area after the debris flow disasters (From locations 1 and 2 in Figure 4).

\subsection{Results and discussions}

Fig. 6 shows the spatial distribution obtained from planarity value over the study area and representative values are shown in fig. 7. Based on the planarity analysis shown in fig. 6, Low planarity values (less than 5) might represent a 
rough ground surface along the valley of the study area. Result also indicates main valleys, upper mountain areas near the army base, and steep slopes artificially created for residences as very rough areas (Planarity value is less than 3 ). This covers $5 \%$ of the total area (fig. 7). On the other hand, high values of the planarity (over 5) may represent smoother ground surfaces usually representing residence areas including roads and building. Some infrastructures show very high planarity values over 9 and take $2.3 \%$ of the study area (fig. 7 ).

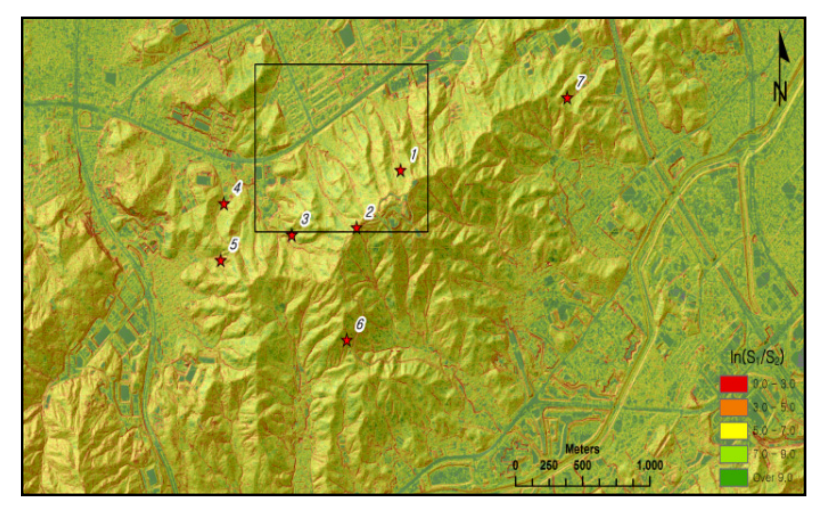

Figure 6: Spatial distribution of planarity values over the study area. Area outlined in the figure is shown in Figure 8.

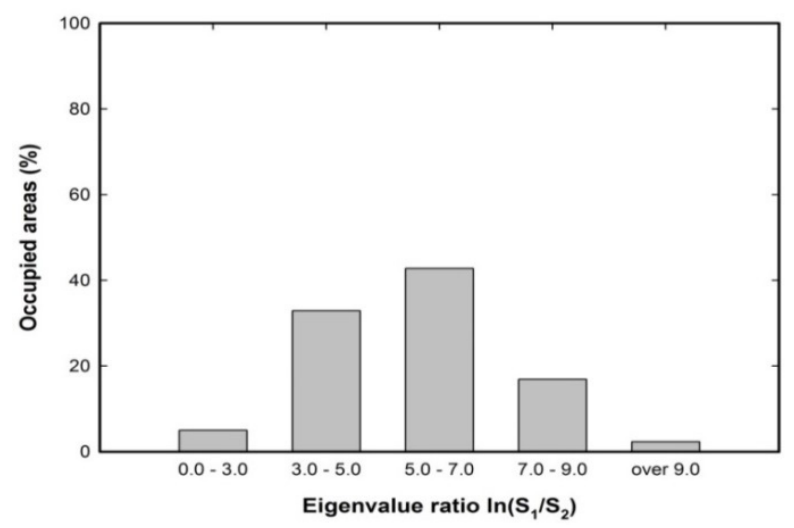

Figure 7: Evaluation of planarity values over the study area.

In this study, statistical evaluation of orientation data well described typical characteristics of geomorphological features on ground surface. These features also provide preliminary information to make the landslide inventory where any landslide related information is absent. Fig. 8 shows a partial distribution of the 
planarity value over the study area, which concentrated on the specific location where the debris flow occurred in 2011. The propagation of the landslide, from initiation to deposition, is relatively wide, it is, therefore, difficult to delineate the exact boundary of the impact due to landslide by using conventional methods.

As shown in fig. 8, a proposed approach based on the analysis of geomorphological features can define the location and boundary of landslide prone areas and may contribute to reduce loss of lives and properties by identifying the movement direction and dispersing border of the future landslides.

Spatial distribution of landslide features would distinguish between stable and unstable domains of the study area and can be used as fundamental elements to achieve landslide hazard assessments with high accuracy.

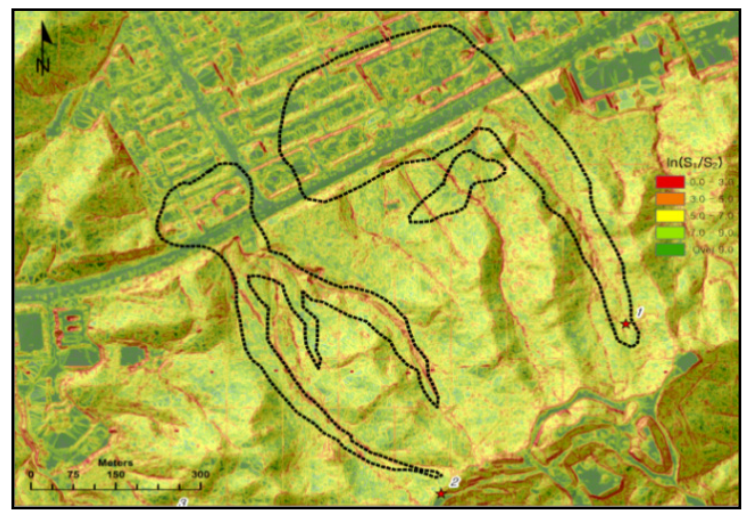

Figure 8: Distribution of the planarity value and boundary of debris flow occurred in 2011.

\section{Relationship between debris flow and climate change}

Increases of temperature and precipitation, which are representative indicators of the climate change may affect the initiation of landslides especially flow type slope disasters such as debris flows. The strong correlation between consequences of the climate change and landslides suggests two hypotheses. Firstly, increasing temperature plays an important role in retreating and melting glacier on high mountain areas such as the Himalayas and Alps. Melting water infiltrates into the slopes and decreases the effective stress of soils, which leads to slope failures.

Increased precipitation, whether it is caused by the increased temperature or other factors, also accelerates the frequency of landslide events. Water content within the ground (about one $\mathrm{m}$ deep from the ground surface), one of the main causal factors initiating landslides, is identified to gradually increase during summer season. It is, therefore, easy to activate the landslides even in a short period of rainfall. 
Figure 9 well illustrates a relationship between precipitation and landslide events in Korea. The fluctuation of precipitation during 2002 to 2011 indicates relatively upper points in 2002, 2003, 2006, and 2011. These years were reported that high casualties due to landslides. The general trend of temperature during the same period also shows a consistent behavior what precipitation has.

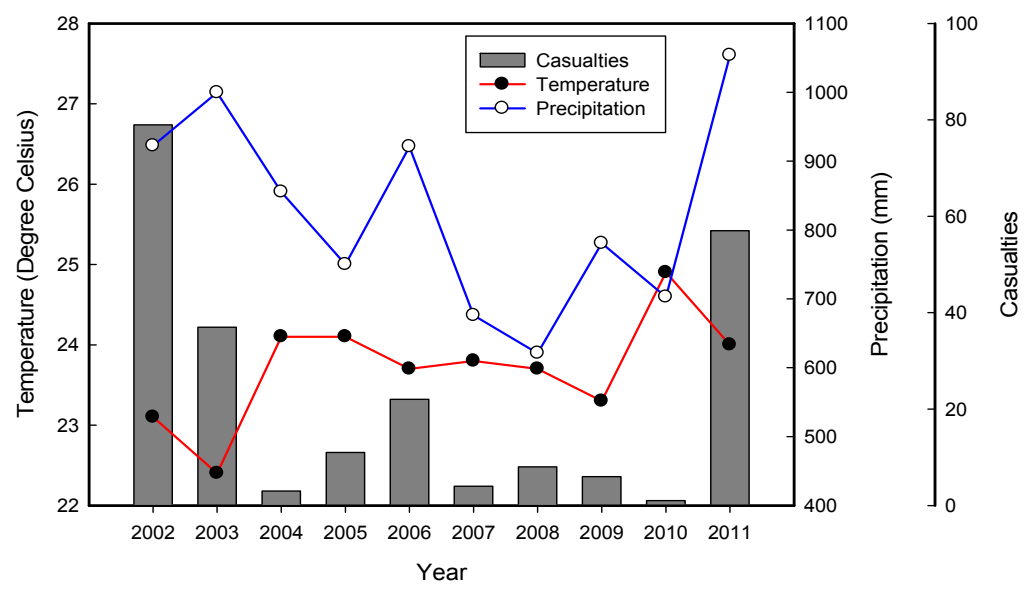

Figure 9: Two key factors of the climate change and casualties of landslide in Korea showing a general trend during 2002-2011.

The climate change may impact all of the hydro-mechanical processes which lead to destabilizing slopes (Laloui et al. [14]). Understanding the pattern of the climate change and relating it to the landslide triggering factors will help to estimate the future landslides and reduce the unnecessary casualties and property damages. The advanced methodologies such as remote sensing technologies and real-time monitoring systems will also strengthen the ability to recognize the relationship between them.

\section{Conclusions}

In this study, we have delineated consequences of climate change and its impact on debris flows, a common landslide in Korea especially summer season. A new approach showing distinct characteristics of geomorphological features on the ground surface is proposed. It provides a guideline between stable and unstable domains of the study area. More physical investigations on specific values which characterize those domains are, however, needed before considering it as a significant parameter in the landslide hazard assessment.

Considering a future tendency of the climate change and its consequences such as modified temperature and precipitation patterns, landslide events will increase and it is the time to develop more reliable technologies to understand physical mechanisms and monitor their behaviors. 


\section{References}

[1] World Meteorological Organization (WMO), WMO Greenhouse Gas Bulletin, 2011.

[2] National Institute of Environmental Research (NIER), A report on the 2010 climate change evaluation, 2011.

[3] Korea Meteorological Administration (KMA), Understanding of the climate change and applying the climate change scenario (I). 2008.

[4] Intergovernmental Panel on Climate Change (IPCC), Climate change, 2007: Impacts, adaptation and vulnerability, Cambridge University Press. 2007.

[5] Pirulli, M. and Sorbino, G., Assessing potential debris flow runout: a comparison of two simulation models. Natural Hazards and Earth System Sciences, 8, pp. 961-971, 2008.

[6] Hobson, R.D., Spatial Analysis in Geomorphology, Surface roughness in topography: quantitative approach, Methuen and Co Ltd., London, Great Britain, pp. 221-245, 1972.

[7] Watson, G.S., Statistics of orientation data. Journal of Geology, 74, pp. 786-797, 1966.

[8] Woodcock, N.H., Specification of fabric shapes using an eigenvalue method. Geological Society of America Bulletin, 88, pp. 1231-1236, 1977.

[9] Mark, D.M., On the interpretation of till fabrics. Geology, 2, pp. 101-104, 1974.

[10] Guth, P.L., Concepts and Modelling in Geomorphology: International Perspectives, Eigenvector analysis of digital elevation models in a GIS: geomorphometry and quality control, Terrapub, Tokyo, pp. 199-220, 2003.

[11] McKean, J. and Roering, J., Objective landslide detection and surface morphology mapping using high-resolution airborne laser altimetry. Geomorphology, 57, pp. 331-351, 2004.

[12] Kasai, M., Ikeda, M., Asahina, T. and Fujisawa, K., LiDAR-derived DEM evaluation of deep-seated landslides in a steep and rocky region of Japan. Geomorphology, 113, pp. 57-69, 2009.

[13] Cruden, D.M., Methods of calculating the axes of cylindrical folds: a review. Geological Society of America Bulletin, 79, pp. 143-148, 1968.

[14] Laloui, L., Ferrari, A. and Eichenberger, J., Effect of climate change on landslide behavior. Geo-Strata, pp. 36-41, 2010. 